\title{
Same Admission Closure of Temporary Bowel Stomas: Feasibility and Outcomes
}

\author{
Mahim Koshariya, Sudesh Sharda, Pramod K Sharma, A Rai, M C Songra
}

Corresponding author:

Mahim Koshariya MS, FMAS, FIASGO

Associate Professor, Department of

Surgery, Gandhi Medical college \&

462001, India

E-mail:mahimk2000@yahoo.co.uk
Associated Hamidia Hospital Bhopal

Department of Surgery, Gandhi Medical College \& Associated Hamidia Hospital Bhopal, India

\section{ABSTRACT}

Background/Aim: This pilot study was designed to investigate the feasibility to close protective loop stomas during the same hospital admission based on data on morbidity and mortality, health-related quality of life and healthcare-related costs shortly after the initial operation as well as to find out the causes that delay the closure and to compare the same admission closure with the delayed closure.

Methodology: We created a temporary small bowel stoma due to various pathology and these patients were divided into two groups i.e one with early closure group (same admission closure within 2-3 weeks and late closure group more than 12 weeks and the results were compared.

Results: In our study early stoma closure was performed in 20 patients, 6 women and 14 men with mean age 35 years at $16.0 \pm 2.8$ days after first operation, late closure was performed in other 25 patients, 8 women and 17 men with mean age 32 years. The average hospital stay was comparable between the 2 groups $11.62 \pm 9.8$ days after late closure and $9.5 \pm 5.0$ days after early closure. Stoma related complications were reported more in delayed closure group as compared with early closure group.

Conclusions: Based on our study and results obtained, in our opinion in otherwise fit and healthy patients with normal wound healing ,early stoma closure in same admission stay after first operation is better option. Not only does it reduce hospital stay also ensures early return to work.

Key words: ileostomy, bowel stoma, early stoma closure

\section{INTRODUCTION}

Received: 13.02 .2017 traumatic and non-traumatic intestinal pathologies. Diversion of the fecal stream by construction of a stoma is still a common procedure in bowel surgery especially in emergency, despite a trend to avoid stomas. $(1,2)$ In elective surgery 
or in emergency surgery if the local or general conditions are unfavourable a temporary ileostomy or colostomy often is constructed to protect a distal anastomosis. However, it is associated with a wellrecognized morbidity, cost and unproven need for a long delay until closure.

The overall morbidity (e.g. leakage around the appliance, skin dermatitis, high output and prolapse) associated with the construction and takedown of a ileostomy or colostomy varies between different authors and ranges between 10.8 and 69\%. $(3,4)$ This morbidity has an effect on patient's health and psychology, postoperative hospital stay, in-hospital costs (5) and quality of life.

Several individual factors are related to the individual's adaptation to life with a stoma including age, (6) socio-economic profile, (7) personality (8) and sex. (9) Studies have shown inferior quality of life in patients with a stoma compared with those who underwent similar procedures without stoma formation. (10-14)

Stoma closure is a frequently performed procedure for temporary enterostomy in surgical practice. Reversal of a temporary ileostomy is generally associated with a low mortality. (15) However, ostomy reversal may cause complications requiring reoperation, and a recently published review found major complications ranging from $0 \%$ to $7-9 \%$ and minor complications varying from $4-5 \%$ to $30 \%$. (16) Although reversal of the temporary stoma resulted in an increase in quality of life. (10)

This temporary stoma is usually closed 9 to 12 weeks later (17) although currently there is no evidence that this period is required for complete healing of the bowel anastomosis. $(18,19,20)$

In a developing country like India, enterostomies are ill managed by the patients due to poor education, poverty and unreliable supply of collecting appliances. Therefore, early closure of the stoma could be considered if the patient is physically fit to be operated on again.

This pilot study was designed to investigate the feasibility to close protective loop stomas during the same hospital admission based on data on morbidity and mortality, health-related quality of life and healthcare-related costs shortly after the initial operation as well as to find out the causes that delay the closure and to compare the same admission closure with the delayed closure.

\section{METHODOLOGY}

Between October 2004 and October 2005, in the
Department of Surgery, Gandhi Medical College and associated Hamidia Hospital Bhopal, We created a temporary small bowel stoma in 51 patients and closed in 45 patients, 18 women and 27 men, mean age 33.5 years (range 24-83). 16 patients had a loop ileostomy above a distal anastomosis because of Typhoid perforation, after traumatic perforation $(N=7)$, for bowel ischemia $(N=5)$ or tuberculous perforation $(N=3)$ and sigmoid volvulous $(N=4)$, for caecal perforation $(N=4)$ or others $(\mathrm{N}=6)$.

The cases were closely monitored in the postoperative period after stoma formation and were evaluated for their, fitness for early closure, regularly after the 7th post operative day. When a patient was found fit for early closure the distal loop contrast study was done with a water-soluble contrast one day prior to operation.

Patients with age 12 years or below, with nonhealing of distal bowel perforation or with persistent postoperative instability or poor general condition, stoma with mucous fistula, steroids in postoperative period or with wound Infection were excluded from early closure group. Patients receive complete oral and written information about the trial, and a written consent has to be signed.

Patients in the intervention group will have the stoma reversed 14-21 days after stoma creation, and patients in the control group will have the stoma reversed after a minimum of 12 weeks.

Closure was performed under general anesthesia with similar prophylactic antibiotic at the time of the incision was given. The elective incision was associated with resection of the stoma and bowel anastomosis or simple closure and closures is done in double layer with 3-0 polyglactin acid thread, the skin was closed with a loose suture.

Per operative blood loss and the time taken for surgery were recorded. In post operative period patients course were recorded. In follow up the patients were routinely called two weeks after the discharge and then monthly for three more months then 6 monthly. All patients will be monitored closely in relation to complications, health-related quality of life and costs.

\section{RESULTS}

Early closure was performed in 20 patients, 6 women and 14 men, mean age 35 years (range 26-83) at $16.0 \pm 2.8$ days after the first operation. The closure was performed in $2 \mathrm{nd}$ week $(\mathrm{N}=13)$ and 3 rd week $(\mathrm{N}=7)$. 
Late closure was performed in the other 25 patients, 8 women and 17 men, mean age 32 years, (age range 26-58) $12.2 \pm 3.7$ weeks after the initial operation. Various factors were responsible for delayed closure (table 1).

The mean operative time taken was $96 \pm 3.15$ mins in delayed closure group and $84 \pm 5.85$ mins in early closure group ( $p$ value $<0.0001$ ). Mean per operative blood loss was $44 \pm 4.8 \mathrm{ml}$ in delayed closure group and $46 \pm 4.2 \mathrm{ml}$ in early closure group ( $p$ value $=0.15$ ) (table 2).

The average hospital stay after closure was comparable between the two groups: $11.62 \pm 9.8$ days after late closure and $9.5 \pm 5.0$ days after early closure. Total mean hospital stay, calculated from the date of the initial admission, was longer in the late closure group ( $36.9 \pm 12.6$ days for two stays, $24.3 \pm 13.6$ days and $11.6 \pm 9.8$ days) than in the early closure group (30.1 \pm 8.6 days in one stay) (table 2).

There were 3 patients in delayed closure group presented with leak and none from early closure group ( $p$ value $=0.24)$. This leak was not from anastomotic dehiscence but a missed iatrogenic tear, which was perhaps made during the dissection. Wound infection presented in 6 patients in delayed closure group and 3 patients in early closure group $(p$ value $=0.71) .1$ patient presented with small bowel obstruction in delayed closure group and 1 patient presented with small bowel obstruction and 1 with chest infection in early closure group and there was no mortality after closure of stoma in any of the group (table 2).

Stoma related complications were reported in 18 patients in delayed closure group and in that parastomal skin excoriation/erythema $(n=13)$ is most frequently encountered stoma related complication
Table 1 - Showing various factors that led to delay in closure

\begin{tabular}{lcc}
\hline Causes & Cases & Percentages \\
\hline Wound infection & 9 & 36 \\
\hline Low BMI & 5 & 20 \\
\hline Chest Complications & 4 & 16 \\
\hline Hypoprotienemia & 3 & 12 \\
\hline Distal Bowel Leak & 2 & 8 \\
Deranged Renal Function & 1 & 4 \\
\hline Not giving Consent & 1 & 4 \\
\hline & & \\
- Wound infection $\quad$ - Low BMI & - Chest Complications \\
- Hypoprotienemia & - Distal Bowel Leak & - Deranged Renal Function \\
- Not giving Consent &
\end{tabular}

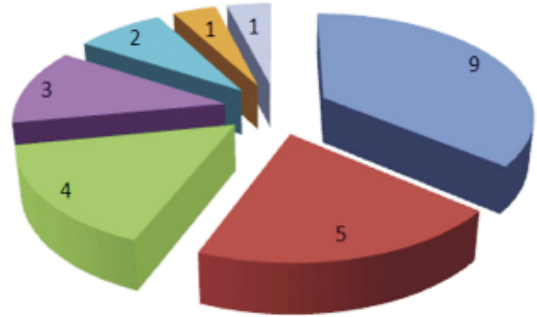

and in 7 patients in early closure group ( $p$ value $=0.018$ ) (table 3).

\section{DISCUSSION}

An intestinal stoma is an opening of intestine on the anterior abdominal wall made surgically. (21) Stoma creation is a treatment that eliminates disease, relieves pain and improves health, whereby stoma creation may also have a positive impact. (22) Shock, marked blood loss, significant faecal contamination, associated injuries, time till presentation and multiplicity of injury

Table 2 - Comparing various parameters between delayed vs early stoma closure group

\begin{tabular}{|c|c|c|c|}
\hline Group & Delayed closure group & Early closure group & $p$ value * \\
\hline Total patients & 25 & 20 & \\
\hline Mean operation time (in mins) & $96 \pm 3.15$ & $84 \pm 5.85$ & $<0.0001$ \\
\hline Mean per operative blood loss (in ml) & $44 \pm 4.8$ & $46 \pm 4.2$ & 0.15 \\
\hline Average hospital stay after closure (in Days) & $11.62 \pm 9.8$ & $9.5 \pm 5.0$ & 0.38 \\
\hline Total mean hospital stay (in Days) & $36.9 \pm 12.6$ & $30.1 \pm 8.6$ & 0.046 \\
\hline Stoma leak & 3 & 0 & 0.24 \\
\hline Wound infection & 6 & 3 & 0.71 \\
\hline Small Bowel Obstruction & 1 & 1 & 1 \\
\hline Chest Infections & 0 & 1 & 0.44 \\
\hline Mortality & 0 & 0 & 1 \\
\hline
\end{tabular}

* $p$ value $<0.05$ is statistically significant 
Table 3 - Comparing stoma related complication between delayed vs early stoma closure group

\begin{tabular}{|c|c|c|c|c|}
\hline S. NO. & Complication & Delayed closure group & Early closure group & p value* \\
\hline 1. & Parastomal skin excoriation/erythema & 13 & 3 & \\
\hline 2. & Hypocalcemia & 1 & 1 & \\
\hline 3. & Parastomal Hernia & 1 & 0 & \\
\hline 4. & Prolapse & 1 & 2 & \\
\hline 5. & Dehydration & 1 & 1 & \\
\hline \multirow[t]{2}{*}{6} & Psychosis & 1 & - & \\
\hline & TOTAL & 18 & 7 & 0.018 \\
\hline
\end{tabular}

* $p$ value $<0.05$ is statistically significant

are important factors favouring stoma formation than primary repair. (23) A stoma can produces social, domestic and psychological upsets. These can be early including metabolic derangements, skin irritation, ischaemia and stoma retraction. Late complications are parastomal hernia, prolapse and stenosis. Parenteral nutritional support may also be needed if the stoma is very proximal, with the infectious and other risks related to insertion of a central venous catheter. The different problems encountered in these patients prompted us to undertake this study of early stoma closure in selected patients. Two prerequisites had to be met in our study. First the closure had to be performed late enough to allow the anastomosis to heal (protective role of the stoma). The risk of anastomotic leak is maximal from day 5 to day 7 postoperatively. (24) Likewise; the stoma had to be closed early enough to avoid excessive postoperative inflammatory reactions which could compromise peristomal dissection. We thus choose 14 days as the average delay before stoma closure. Using this time, we found that, despite the selection bias which excluded patients with a high risk of leak, early closer of small bowel stomas is feasible and that it significantly reduces the total duration of hospitalization without increase in morbidity and mortality. We reported significantly less operative time, insignificantly more blood loss and higher chest complication in early stoma closure group as compare to delayed closure group. We found a higher rate of wound infection after late closure than after early closure as against study by Velmahos et al. (25) This difference was not significant in our study, but probably only because of the small number of patients in each group. There is also significantly higher stoma related complications reported in delayed closure group as compared to early closure group.

\section{CONCLUSION}

Same admission ostomy closure is based upon sound principles. Collagen synthesis and content of stoma wound are optimal, seven to eleven days after the stoma construction. Closure of ostomies during this proliferative phase of wound healing will ensure better anastomotic healing and strength. Hence, after radiological confirmation of the healing of the primary process or injury distal to the stoma, same admission closure can be safely undertaken one week after stoma construction. Delayed (after 8 weeks) closure has been practiced to date to ensure repletion of lean body mass, resolution of peritonitis, sepsis, and inflammation in the region of the primary pathology, and healing of anastomosis or injuries distal to the stoma.

In our opinion, in otherwise fit and healthy patients with normal wound healing same admission closure is an attractive option. Not only does it reduce hospital stay but also ensures early return to work. Even more important, in developing countries where healthcare systems are not well established and poverty is rife, same admission closure ensures that patients never have to learn stoma care, purchase appliances or deal with stoma related problems chores.

\section{REFERENCES}

1. Mealy K, Burke P, Hyland J. Anterior resection without a defunctioning colostomy: questions of safety. Br J Surg. 1992 Apr;79(4):305-7.

2. Mealy K, Salman A, Arthur G. Definitive one-stage emergency large bowel surgery. Br J Surg. 1988 Dec;75(12):1216-9.

3. Wexner SD, Taranow DA, Johansen OB, Itzkowitz F, Daniel N, Nogueras J, et al: Loop ileostomy is a safe option for fecal diversion. Dis Colon Rectum. 1993 Apr;36(4):349-54.

4. Feinberg SM, McLeod RS, Cohen Z. Complications of loop ileostomy. Am J Surg. 1987 Jan;153(1):102-7.

5. Sagar PM, Lewis W, Holdsworth PJ, Johnston D. One-stage restorative proctocolectomy without temporary defunctioning ileostomy. Dis Colon Rectum. 1992 Jun;35(6):582-8. 
6. Ma N, Harvey J, Stewart J, Andrews L, Hill AG. The effect of age on the quality of life of patients living with stomas: a pilot study. ANZ J Surg. 2007 Oct; $77(10): 883-5$.

7. Holzer B, Matzel K, Schiedeck T, Christiansen J, Christensen P, Rius J, et al. Do geographic and educational factors influence the quality of life in rectal cancer patients with a permanent colostomy? Dis Colon Rectum. 2005 Dec;48(12):2209-16.

8. Siassi M, Hohenberger W, Lösel F, Weiss M. Quality of life and patient's expectations after closure of a temporary stoma. Int $\mathrm{J}$ Colorectal Dis. 2008 Dec;23(12):1207-12. doi: 10.1007/s00384-0080549-2. Epub 2008 Aug 7.

9. Hamashima C. Long-term quality of life of postoperative rectal cancer patients. J Gastroenterol Hepatol. 2002 May; 17(5):571-6.

10. Engel J, Kerr J, Schlesinger-Raab A, Eckel R, Sauer H, Hölzel D. Quality of life in rectal cancer patients: a four-year prospective study. Ann Surg. 2003 Aug;238(2):203-13.

11. Sprangers MA, Taal BG, Aaronson NK, te Velde A. Quality of life in colorectal cancer. Stoma vs. nonstoma patients. Dis Colon Rectum. 1995 Apr;38(4):361-9.

12. Butler DL. Early postoperative complications following ostomy surgery: a review. J Wound Ostomy Continence Nurs. 2009 Sep-Oct; 36(5):513-9; quiz 520-1. doi: 10.1097/WON.0b013e3181b35eaa.

13. Cottam J, Richards K, Hasted A, Blackman A. Results of a nationwide prospective audit of stoma complications within 3 weeks of surgery. Colorectal Dis. 2007 Nov;9(9):834-8. Epub 2007 Aug 2.

14. Shabbir J, Britton DC. Stoma complications: a literature overview. Colorectal Dis. 2010 Oct;12(10):958-64.

15. Chow A, Tilney HS, Paraskeva P, Jeyarajah S, Zacharakis E, Purkayastha $\mathrm{S}$. The morbidity surrounding reversal of defunctioning ileostomies: a systematic review of 48 studies including 6,107 cases.
Int J Colorectal Dis. 2009 Jun;24(6):711-23. doi: 10.1007/s00384009-0660-z. Epub 2009 Feb 17.

16. Hindenburg T, Rosenberg J. Closing a temporary ileostomy within two weeks. Dan Med Bul 2010;57:1-5.

17. Gooszen AW, Geelkerken RH, Hermans J, Lagaay MB, Gooszen HG. Temporary decompression after colorectal surgery: randomized comparison of loop ileostomy and loop colostomy. Br J Surg. 1998 Jan;85(1):76-9.

18. Winslet MC, Barsoum G, Pringle W, Fox K, Keighley MR. Loop ileostomy after ileal pouch-anal anastomosis: is it necessary? Dis Colon Rectum. $1991 \mathrm{Mar} ; 34(3): 267-70$.

19. Keighley MR, Williams NS. Ileostomy. In: Keigley MR, Williams NS: Surgery of the anus, rectum and colon. Philadelphia: WB Saunders; 1993. p. 139-99.

20. Senapati A, Nicholls RJ, Ritchie JK, Tibbs CJ, Hawley PR. Temporary loop ileostomy for restorative proctocolectomy. Br J Surg. 1993 May; 80(5):628-30.

21. Irving $\mathrm{MH}$, Hulme $\mathrm{O}$. $\mathrm{ABC}$ of colorectal diseases. Intestinal stomas. BMJ. 1992 Jun 27;304(6843):1679-81.

22. Rauch P, Miny J, Conroy T, Neyton L, Guillemin F. Quality of life among disease-free survivors of rectal cancer. J Clin Oncol. 2004 Jan 15; 22(2):354-60.

23. Memon AS, Memon JM, Malik A, Soomro AG. Pattern of acute intestinal obstruction. Pakistan Journal of Surgery. 1995;11:91-3.

24. Rolandelli R, Roslyn JJ. Surgical management and treatment of sepsis associated with gastrointestinal fistulas. Surg Clin North Am. 1996 Oct;76(5):1111-22

25. Velmahos GC, Degiannis E, Wells M, Souter I, Saadia R. Early closure of colostomies in trauma patients - a prospective randomized trial. Surgery. 1995 Nov;118(5):815-20. 